\title{
Pros and cons of using systemic acitretin in the paediatric population
}

\author{
Magdalena Sadowska, Joanna Narbutt, Małgorzata Skibińska, Aleksandra Lesiak \\ Department of Dermatology, Paediatric Dermatology and Oncology, Medical University of Lodz, Lodz, Poland \\ Adv Dermatol Allergol 2022; XXXIX (1): 34-38 \\ DOI: https://doi.org/10.5114/ada.2020.98558
}

\begin{abstract}
Acitretin, a synthetic analogue of vitamin A is widely used in dermatology. It has an important role in the treatment of psoriasis and keratinization disorders. In adults its safety and efficacy has been proven in many studies, but there are some concerns regarding the use of acitretin in paediatric population, especially in high doses and as a long-term therapy. In this article we present the main indications of acitretin in children as well as the positive and negative aspects of acitretin treatment in this age population.
\end{abstract}

Key words: acitretin, paediatric use, psoriasis, disorders of keratinisation.

\section{Introduction}

Acitretin, a synthetic retinoid, plays an important role in dermatologic treatments. It is widely used in the therapy of psoriasis and keratinization disorders (Table 1) [1]. There is a lot of evidence of its safety in adult patients, but there are some concerns and doubts about acitretin therapy in children. The aim of this article is to present pros and cons of using acitretin in paediatric population.

Acitretin is a non-immunosuppressive vitamin A analogue, an active metabolite of etretinate. By interfering with the expression of epidermal growth factor genes it reduces epidermal cell proliferation and increases keratinocyte differentiation. Acitretin has also immunomodulatory effects, inhibits production of vascular endothelial growth factor and neutrophil migration [1-3].

\section{Acitretin use in paediatric dermatology \\ Psoriasis}

Acitretin is widely used in the treatment of psoriasis. It is a first-line drug for generalized pustular psoriasis [4]. Acitretin is also effectively used in the treatment of extensive plaque psoriasis with psoriasis area severity index (PASI) of more than 10, erythrodermic psoriasis, severe disabling palmoplantar psoriasis, palmoplantar pustulosis [3-6]. Its major advantage is being a non-immunosuppressive drug, thus when patients have contraindications to immunosuppressants, acitretin is a good choice. Acitretin is not effective in patients with psoriatic arthritis [7, 8].

In a multicentre cohort study of 289 children with psoriasis (age from 9 to 14 years), 61 were treated with acitretin $(0.3-0.5 \mathrm{mg} / \mathrm{kg} /$ day, mean survival of acitretin - 15.4 months). $47.5 \%$ of patients on acitretin therapy achieved at least PASI-75 response. PASI-75 and more response rate to methotrexate and cyclosporine was observed in $34.1 \%$ and $40 \%$ of patients respectively [9].

In the multicentre retrospective study of the use of acitretin in children (18 patients, aged from 2 to 14 years, mean dose of $0.41 \mathrm{mg} / \mathrm{kg} /$ day, mean total treatment duration $-22.7 \pm 12.0$ months) for plaque psoriasis, acitretin was moderately effective (44.4\% of patients achieved a PASI-75) and well-tolerated treatment. The response rate to acitretin was comparable to the response rate in adults [10].

Acitretin may be used in combination with phototherapy [7]. Both NB-UVB (narrowband UVB) and PUVA (psoralen-UVA) may be used with acitretin, resulting in better outcomes and lower doses of both agents needed. It is also helping to reduce side effects $[4,11,12]$. Combining retinoids with phototherapy is preferred for plaquetype psoriasis as it allows for a higher clearance rate and lower doses of UV and retinoids are needed [13].

In the retrospective study (from June 2013 to June 2014) in 19 French centres comparing systemic treatments in 154 children with psoriasis, acitretin was the most frequent therapy used. Acitretin was mainly used

\footnotetext{
Address for correspondence: Magdalena Sadowska MD, Department of Dermatology, Paediatric Dermatology and Oncology, Medical University of Lodz, 1/5 Kniaziewicza St, Lodz, Poland, phone/fax: +48 42251 61 92, e-mail: magdalena.sadowska.umed@gmail.com Received: 6.07.2020, accepted: 21.07.2020.
} 
Table 1. Acitretin in paediatric dermatoses

\begin{tabular}{|c|c|c|c|c|}
\hline Indication & Age & $\begin{array}{l}\text { Number } \\
\text { of patients }\end{array}$ & Dose & Study \\
\hline Psoriasis & 9-14 years & 61 & $0.3-0.5 \mathrm{mg} / \mathrm{kg} / \mathrm{day}$ & [9] \\
\hline Plaque psoriasis & $2-14$ years & 18 & $\begin{array}{l}0.2-0.5 \mathrm{mg} / \mathrm{kg} / \mathrm{day} \\
\text { Maintenance dose }-0.41 \mathrm{mg} / \mathrm{kg} / \text { day }\end{array}$ & [10] \\
\hline $\begin{array}{l}\text { Plaque psoriasis, pustular psoriasis, } \\
\text { erythrodermic psoriasis, guttate psoriasis, } \\
\text { palmoplantar psoriasis, nail psoriasis }\end{array}$ & $1-17$ years & 154 & No information & [14] \\
\hline Generalized pustular psoriasis & 3.5 years & 1 & $\begin{array}{c}1.0 \mathrm{mg} / \mathrm{kg} / \mathrm{day} \\
\text { Maintenance dose }-0.3 \mathrm{mg} / \mathrm{kg} / \text { day }\end{array}$ & [4] \\
\hline Generalized pustular psoriasis & $\begin{array}{l}5 \text { months- } \\
9 \text { years }\end{array}$ & 15 & $\begin{array}{l}0.6-1.0 \mathrm{mg} / \mathrm{kg} / \mathrm{day} \\
\text { Maintenance dose }-0.2-0.3 \mathrm{mg} / \mathrm{kg} / \mathrm{day}\end{array}$ & [6] \\
\hline Infantile pustular psoriasis & 2.5 months & 1 & $\begin{array}{c}0.5-0.7 \mathrm{mg} / \mathrm{kg} / \mathrm{day} \\
\text { Maintenance dose }-0.3 \mathrm{mg} / \mathrm{kg} / \text { day }\end{array}$ & [21] \\
\hline Generalized pustular psoriasis & 1.5 months & 1 & $\begin{array}{c}1.0 \mathrm{mg} / \mathrm{kg} / \mathrm{day} \\
\text { Maintenance dose }-0.4 \mathrm{mg} / \mathrm{kg} / \mathrm{day}\end{array}$ & [22] \\
\hline $\begin{array}{l}\text { Lamellar ichthyosis, bullous ichthyosiform } \\
\text { erythroderma, non-bullous ichthyosiform, } \\
\text { Sj gren-Larsson syndrome, Darier's disease, } \\
\text { palmoplantar keratoderma, erythrokeratoderma, } \\
\text { Conradi-Hünermann syndrome }\end{array}$ & $1.9-16.6$ years & 29 & $\begin{array}{c}0.38-0.54 \mathrm{mg} / \mathrm{kg} / \text { day } \\
\text { Mean dose }-0.47 \mathrm{mg} / \mathrm{kg} / \text { day }\end{array}$ & [15] \\
\hline $\begin{array}{l}\text { Darier's disease, bullous ichthyosiform } \\
\text { erythroderma, lamellar ichthyosis }\end{array}$ & $4-7$ years & 3 & $\begin{array}{c}0.8-1.0 \mathrm{mg} / \mathrm{kg} / \mathrm{day} \\
\text { Maintenance dose }-0.2-0.3 \mathrm{mg} / \mathrm{kg} / \text { day }\end{array}$ & [16] \\
\hline
\end{tabular}

as a first-line treatment and the efficacy rate was the best in plaque and pustular psoriasis. Adverse effects were frequent, but most of them were mild and only 6 adverse effects induced stopping of acitretin. In this study among systemic treatments, the combination of acitretin with phototherapy was most efficacious [14].

\section{Disorders of keratinization}

Acitretin is the treatment of choice for inherited disorders of keratinization [15]. These conditions include bullous ichthyosiform erythroderma, non-bullous ichthyosiform erythroderma, lamellar ichthyosis, Harlequin ichthyosis, Sjögren-Larsson syndrome, Conradi-Hünermann syndrome, Darier's disease, palmoplantar keratoderma, erythrokeratoderma, pityriasis rubra pilaris and pachyonychia congenita [5, 15-19]. In the severe variants of ichthyoses oral retinoids may be even lifesaving [5, 20].

In the retrospective investigation of long-term acitretin monotherapy in three children with keratinization disorders (Darier's disease, bullous ichthyosiform erythroderma, lamellar ichthyosis) all the patients responded well to the therapy (the starting dose was $0.8-1.0 \mathrm{mg}$ / $\mathrm{kg} /$ day) and they were continuing the treatment at the maintenance dose (0.2-0.3 mg/kg/day) for $12-13$ years with a good effect and good tolerance of the drug [16].

\section{Other - acitretin and infants}

Acitretin may be also an effective therapeutic option for very young patients. There are some cases in the lit- erature proving safety of using acitretin even in infants. A 2.5-month-old infant with infantile pustular psoriasis was successfully treated with acitretin $(0.5-0.7 \mathrm{mg} / \mathrm{kg} /$ day). The only adverse effect was a slightly increased level of serum triglycerides, but it returned to normal after reducing the dose to $0.3 \mathrm{mg} / \mathrm{kg} /$ day [21]. In another case report a 6-week-old infant with generalized pustular psoriasis was initiated at $1 \mathrm{mgkg} /$ day of acitretin, the dose was then reduced to $0.4 \mathrm{mg} / \mathrm{kg} /$ day resulting in complete resolution of the disease with no relapse after stopping the treatment [22].

\section{Adverse effects}

Retinoids are known for causing a number of frequent adverse effects, but most of them are dose dependent and reversible. Comparing to adult population there is not a lot of studies considering adverse effects of acitretin in children.

The most common adverse effects are mucocutaneous, among which the most frequent is dryness of lips. Other include dry mouth, cheilitis, also occasionally stomatitis, gingivitis and taste disturbance may occur. Dryness with inflammation of mucous membrane and transitional epithelia may lead to epistaxis, rhinitis, conjunctivitis and xerophthalmia. Increased hair loss, nail fragility, thinning and scaling of the skin and paronychia have been also observed. Rarely photosensitivity reactions may occur [2, 5, 7, 23]. 
During acitretin therapy a transient elevation of liver enzymes may be observed. However, severe hepatotoxic reactions are rare $[2,5,7,23,24]$.

Acitretin exerts an impact on alteration of the lipid profile. Usually, hyperlipidaemia is dose dependent and reversible. The most frequent is the elevation of triglycerides. Hypercholesterolemia and decreased high-density lipoprotein levels may also occur [2, 5, 7].

Retinoids can be also responsible for causing blurred vision, headaches and reduced night vision $[5,7]$. Joint pain and myalgia may be occasionally reported by patients on acitretin therapy $[8,25]$.

The overdose symptoms are similar to vitamin A toxicity and include headache, nausea, vomiting, drowsiness and vertigo. Acitretin should be discontinued if these symptoms occur [2].

In the recent retrospective study of 174 paediatric patients treated with acitretin (mean maximum dose $0.45 \mathrm{mg} / \mathrm{kg} /$ day), clinical adverse effects occurred in $24 \%$, among which the most common were increased skin irritation (10.3\%) and dry lips (9.2\%). Laboratory adverse effects affected $22.4 \%$ of patients with abnormal triglycerides (10\%) and abnormal alkaline phosphatase levels (5.9\%) as the most frequent ones. Only $4.1 \%$ of patients had to stop the treatment because of the laboratory adverse effects [26]. Therefore, in this population acitretin was a safe drug.

In a multicentre cohort study of 289 children with psoriasis (aged from 9 to 14 years), 61 were treated with acitretin (0.3-0.5 mg/kg/day). $70.7 \%$ of patients did not experience any adverse effects, mucocutaneous adverse effects occurred in $25.9 \%, 1.7 \%$ had hyperlipidaemia, $1.7 \%$ experienced nausea. There were no cases of abnormal transaminase levels observed [9].

The retrospective review conducted at 20 centres in North America and Europe assessing patterns of use and relative risks of systemic agents for moderate to severe psoriasis in children included 390 children, among which acitretin was used by 57 patients. During acitretin therapy adverse effects occurred in 38 patients. The most frequent was cheilitis (29.8\%), xerosis (26.3\%), hyperlipidaemia (14\%), elevated transaminase levels (7\%) and epistaxis (5.3\%) [27].

Skeletal adverse effects are a major concern [28, 29] and often the use of acitretin in children is limited by the worries about its long-term safety. However, there is lack of prospective, controlled long-term trials proving association between acitretin treatment and skeletal changes in children. There are some reports describing premature epiphyseal closure, skeletal hyperostosis and extraosseous calcification and other skeletal abnormalities in children treated with long-term systemic etretinate (for 5 years and 5 months up to 9.6 years) [28, 30]. In the study of 10 children with psoriasis treated with etretinate, in one child, focal osteoporosis of one tibia was observed after 7 years of the treatment. However, no adverse effects on children's development and growth occurred [31].

Sometimes skeletal changes may be present at the start of retinoid therapy or in control groups, so the interpretation of the association between retinoid therapy and bone toxicity may be difficult [32].

In the retrospective study describing 23 patients with disorders of keratinization treated with oral retinoids for up to 25 years, only 1 out of 10 patients, who had radiological investigations developed diffuse idiopathic skeletal hyperostosis (DISH) syndrome after 21 years of treatment. This patient continued the therapy due to successful skin effects and there were no deteriorations of the spinal changes over the next 4 years of observation. Two of the patients in this study had started the treatment with oral retinoids at a young age (4.2 and 5.4 years), after 23.8 and 8.5 years respectively there were no signs of skeletal adverse effects [33].

In the systematic review of 15 studies in 2011 the authors showed no evidence for skeletal toxicity of retinoids and no association with a daily or cumulative dose and overall duration of treatment [13].

In the retrospective study of probably the longest continuous acitretin monotherapy (0.2-0.3 mg/kg/day) for hyperkeratotic disorders, three males started the treatment at the age of 4,7 and 5 years and continued the therapy for the next $12-13$ years. The cumulative doses of acitretin were $60-80 \mathrm{~g}$, all the blood tests including lipid panel, liver and kidney function were normal. There were no skeletal abnormalities or growth retardation [16].

Some adverse effects may be more common in adults because of the often coexisting comorbidities in older patients [34]. The risk of hepatotoxicity is higher in patients with co-factors like obesity, diabetes mellitus, hepatotoxic drugs, alcohol intake. Thus, children may be less prone to hepatotoxic reactions as these comorbidities are less likely to exist in paediatric patients [35].

As children usually have good lipid metabolism and hepatic function some authors suggest that they may be less likely to experience adverse effects compared to adults on equivalent doses, but no prospective clinical trials have been conducted [10].

\section{Monitoring guidelines}

As there are no guidelines for monitoring the use of acitretin in children, some authors suggest following the guidelines for adults. Blood tests before starting the treatment should include liver function tests (transaminases, $\gamma$-glutamyltransferase, alkaline phosphatase), fasting lipid panel, renal function test (creatinine), blood count, fasting glucose and pregnancy test in young women of child-bearing age $[2,26,36,37]$. The vitamin D level may also be checked before the treatment [26].

Blood tests (liver enzymes, fasting lipid panel) should be performed every $2-4$ weeks for the first 2 months and 
after that, every 3 months of the therapy [2]. According to the British Association of Dermatologists, if transaminases are elevated to three times their upper limit, acitretin is advised to be discontinued [2]. In Table 2 we present suggested laboratory monitoring during acitretin therapy.

There is no need for routine $X$-rays monitoring if the patient is asymptomatic because of the risk from exposure to radiation [2]. However, it is recommended to monitor the growth regularly in children treated with acitretin and perform targeted $X$-rays in case of atypical complaints [37]. In the study of 28 patients (aged from 1 to 13 years) with severe inherited keratinization disorders receiving acitretin therapy, body height and weight were chosen to be monitored. There was no negative effect observed on the growth and development of those children [38].

Some authors suggest performing radiography before long-term treatment [37]. But according to expert opinion based on the systematic review, experts agreed not to recommend any bone monitoring [39].

Acitretin is not recommended in adolescent females of child-bearing age, because of its teratogenic properties. There is a necessity of effective contraception for at least 4 weeks before and during the treatment with acitretin, and for 3 years after discontinuation of the drug. Patients must be informed about the risk and possible consequences [2]. Pregnancy tests must be performed every month during the treatment and up to 2 years after therapy according to the European guidelines or even up to 3 years according to the American standards [2, 3, 37]. Some authors suggest using the alternative drug in girls from the age of 12 years old [26].

\section{Conclusions}

The advantages of acitretin include non-immunosuppressive properties, no interfering with vaccination, possibility of combination therapy with phototherapy, no cumulative or time dose limitations [9]. Considering the fact that in adults, comorbidities like obesity, diabetes mellitus or alcohol consumption are more often, children may be less prone to some adverse effects. Moreover, the long-term experience of using acitretin in the treatment of psoriasis and keratinization disorders in children indicates its safety and efficacy in paediatric population. However, before staring acitretin therapy in children, risks and benefits of the treatment and risk of untreated disease should be assessed. It can be used in children if in the opinion of the treating physician, the benefits significantly outweigh the risks. Although the recommendations of many scientific societies are not consistent, we presented a lot of evidence indicating benefits of using acitretin in children. However, there is a need of proper evaluation before long-term treatment, as well as regular laboratory and clinical monitoring including growth parameters such as growth charts. More randomized
Table 2. Suggested laboratory monitoring [2, 26, 36, 37]

\begin{tabular}{ll}
\hline Before the & - Pregnancy test \\
treatment & - Liver function tests (transaminases, \\
& - $\gamma$-glutamyltransferase, alkaline phosphatase) \\
& - Renal function test (creatinine) \\
& - Blood count \\
& - Fasting glucose \\
\hline During the & - Pregnancy test \\
treatment & - Liver function tests \\
& - Fasting lipid panel \\
& Blood count \\
& alternatively: \\
& Fasting glucose
\end{tabular}

studies, prospective data and extensive database evaluating efficacy, safety and dosing regimen in children are needed to be performed.

\section{Acknowledgments}

This research was funded by statutory activities of the Medical University of Lodz no. 503/5-064-04/503-01.

\section{Conflict of interest}

Joanna Narbutt has worked as a Consultant or Speaker for AbbVie, Bioderma, Eli Lilly, Janssen, Leo Pharma, Medac, Novartis, Pierre-Fabre, and participated as Principal Investigator or Subinvestigator in clinical trials sponsored by AbbVie, UCB, Galderma, Janssen, Leo Pharma, Pfizer. Aleksandra Lesiak has worked as a Consultant or Speaker for AbbVie, Bioderma, Eli Lilly, Janssen, Leo Pharma, Medac, Novartis, Pierre-Fabre, and participated as Principal Investigator or Subinvestigator in clinical trials sponsored by AbbVie, UCB, Galderma, Janssen, Leo Pharma, Pfizer.

\section{References}

1. Guenther LC, Kunynetz R, Lynde CW, et al. Acitretin use in dermatology. J Cutan Med Surg 2017; 21: 2S-12S.

2. Ormerod AD, Campalani E, Goodfield MJD. British Association of Dermatologists guidelines on the efficacy and use of acitretin in dermatology. Br J Dermatol 2010; 162: 952-63.

3. Marqueling AL, Cordoro KM. Systemic treatments for severe pediatric psoriasis. A practical approach. Dermatol Clin 2013; 31: 267-88.

4. Kopp T, Karlhofer F, Szépfalusi Z, et al. Successful use of acitretin in conjunction with narrowband ultraviolet B phototherapy in a child with severe pustular psoriasis, von Zumbusch type. Br J Dermatol 2004; 151: 912-6.

5. Gautam M, Tahiliani H, Nadkarni N, et al. Acitretin in pediatric dermatoses. Indian J Paediatr Dermatology 2016; 17: 87.

6. Chen P, Li C, Xue R, et al. Efficacy and safety of acitretin monotherapy in children with pustular psoriasis: results from 15 cases and a literature review. I Dermatolog Treat 2018; 29: 353-63. 
7. Subedi S, Yu Q, Chen Z, Shi Y. Management of pediatric psoriasis with acitretin: a review. Dermatol Ther 2018; 31 doi:10.1111/dth.12571.

8. Menter A, Korman NJ, Elmets CA, et al. Guidelines of care for the management of psoriasis and psoriatic arthritis. Section 4. Guidelines of care for the management and treatment of psoriasis with traditional systemic agents. J Am Acad Dermatol 2009; 61: 451-85.

9. Ergun T, Seckin Gencosmanoglu D, Alpsoy E, et al. Efficacy, safety and drug survival of conventional agents in pediatric psoriasis: a multicenter, cohort study. J Dermatol 2017; 44: 630-4.

10. Di Lernia V, Bonamonte D, Lasagni C, et al. Effectiveness and safety of acitretin in children with plaque psoriasis: a multicenter retrospective analysis. Pediatr Dermatol 2016; 33: 530-5.

11. Lebwohl M, York N, York N. Acitretin in combination with UVB or PUVA. J Am Acad Dermatol 1999; 41: 22-4.

12. Armstrong R, Nychay S, Edelstein J. Acitretin plus UVB therapy for psoriasis: comparisons with placebo plus UVB and acitretin alone. J Am Acad Dermatol 1991; 24: 591-4.

13. Sbidian E, Maza A, Montaudié H, et al. Efficacy and safety of oral retinoids in different psoriasis subtypes: a systematic literature review. J Eur Acad Dermatology Venereol 2011; 25 (Suppl. 2): 28-33.

14. Charbit L, Mahé E, Phan A, et al. Systemic treatments in childhood psoriasis: a French multicentre study on 154 children. Br J Dermatol 2016; 174: 1118-21.

15. Lacour M, Mehta-Nikhar B, Atherton Dj, Harper J. An appraisal of acitretin therapy in children with inherited disorders of keratinization. Br J Dermatol 1996; 134: 1023-9.

16. Liang J, Chen $\mathrm{P}$, Chen $\mathrm{H}$, et al. Long-term safety and efficacy of continuous acitretin monotherapy for three children with different severe hyperkeratotic disorders in China. J Dermatol 2018; 45: 1003-8.

17. Zhang X, He Y, Zhou H, et al. Severe ichthyosis-related disorders in children: response to acitretin. J Dermatolog Treat 2007; 18: 118-22.

18. Yang CC, Shih IH, Lin WL, et al. Juvenile pityriasis rubra pilaris: report of 28 cases in Taiwan. J Am Acad Dermatol 2008; 59: 943-8.

19. Gruber R, Edlinger M, Kaspar RL, et al. An appraisal of oral retinoids in the treatment of pachyonychia congenita. J Am Acad Dermatol 2012; 66: e193-9.

20. Ruiz-Maldonado R, Tamayo-Sanchez L, Orozco-Covarrubias ML. The use of retinoids in the pediatric patient. Dermatol Clin 1998; 16: 553-69.

21. Ergin S, Ersoy-Evans S, Şahin S, Özkaya O. Acitretin is a safe treatment option for infantile pustular psoriasis. J Dermatolog Treat 2008; 19: 341-3.

22. Chao PH, Cheng YW, Chung MY. Generalized pustular psoriasis in a 6-week-old infant. Pediatr Dermatol 2009; 26: 352-4

23. Gupta AK, Goldfarb MT, Ellis CN, Voorhees JJ. Side-effect profile of acitretin therapy in psoriasis. J Am Acad Dermatol 1989; 20: 1088-93.

24. Katz HI, Waalen J, Leach EE. Acitretin in psoriasis: an overview of adverse effects. J Am Acad Dermatol 1999; 41 (3 Suppl.): 7-12.

25. Nesher G, Zuckner J. Rheumatologic complications of vitamin a and retinoids. Semin Arthritis Rheum 1995; 24: 291-6.

26. Cave A, Plumptre I, Mellerio JE, et al. The adverse effect profile of Acitretin in a paediatric dermatology population - longitudinal cohort study and recommendations for monitoring. J Am Acad Dermatol 2020. doi:10.1016/j. jaad.2020.03.082

27. Bronckers IMGJ, Seyger MMB, West DP, et al. Safety of systemic agents for the treatment of pediatric psoriasis. JAMA Dermatology 2017; 153: 1147-57.

28. Prendiville J, Bingham EA, Burrows D. Premature epiphyseal closure - a complication of etretinate therapy in children. J Am Acad Dermatol 1986; 15: 1259-62.

29. Halverstam CP, Zeichner J, Lebwohl M. Lack of significant skeletal changes after long-term, low-dose retinoid therapy: case report and review of the literature. J Cutan Med Surg 2006; 10: 291-9.

30. Halkier-Sørensen L, Laurberg G, Andresen J. Bone changes in children on long-term treatment with etretinate. J Am Acad Dermatol 1987; 16: 999-1006.

31. Rosinska D, Wolska H, Jablonska S, Konca I. Etretinate in severe psoriasis of children. Pediatr Dermatol 1988; 5: 266-72.

32. Kilcoyne RF. Effects of retinoids in bone. J Am Acad Dermatol 1988; 19: 212-6.

33. Katugampola RP, Finlay AY. Oral retinoid therapy for disorders of keratinization: single-centre retrospective 25 years' experience on 23 patients. Br J Dermatol 2006; 154: 267-76.

34. Brecher AR, Orlow SJ. Oral retinoid therapy for dermatologic conditions in children and adolescents. J Am Acad Dermatol 2003; 49: 171-82.

35. Carretero G, Ribera M, Belinchón I, et al. Guidelines for the use of acitretin in psoriasis. Actas Dermo-Sifiliográficas 2013; 104: 598-616.

36. Nast A, Jacobs A, Rosumeck S, Werner RN. Methods report: European S3-Guidelines on the systemic treatment of psoriasis vulgaris - Update 2015 - EDF in cooperation with EADV and IPC. J Eur Acad Dermatology Venereol 2015; 29: e1-22.

37. Pathirana D, Ormerod AD, Saiag P, et al. European S3-guidelines on the systemic treatment of psoriasis vulgaris. J Eur Acad Dermatology Venereol 2009; 23 (Suppl. 2): 5-70.

38. Zhang XB, Luo Q, Li CX, et al. Clinical investigation of acitretin in children with severe inherited keratinization disorders in China. J Dermatolog Treat 2008; 19: 221-8.

39. Paul C, Gallini A, Maza A, et al. Evidence-based recommendations on conventional systemic treatments in psoriasis: systematic review and expert opinion of a panel of dermatologists. J Eur Acad Dermatol Venereol 2011; 25 (Suppl. 2): 2-11. 